\title{
Reversible airflow limitation in adults with respiratory infection
}

\author{
H. Melbye*, J. Kongerud**, L. Vorland***
}

Reversible airflow limitation in adults with respiratory infection. H. Melbye, J. Kongerud, L. Vorland. CERS Journals Ltd 1994.

ABSTRACT: The aim of the study was to determine the occurrence of airflow limitation and the frequency of significant reversibility in respiratory infections in adults without known asthma or chronic obstructive pulmonary disease (COPD). We also wanted to study the association between airflow limitation and aetiological agents diagnosed by serological analyses.

Spirometry was performed in $\mathbf{5 7 4}$ adult general practice patients with upper or lower respiratory tract infection, and follow-up measurement was obtained in 429 of them. In the latter group, we also obtained paired sera for analysis of antibodies against respiratory viruses, chlamydial and mycoplasmal agents.

Median forced expiratory volume in one second $\left(\mathrm{FEV}_{1}\right)$ in all patients included was $\mathbf{9 0 \%}$ of predicted; significantly lower in patients with an established diagnosis of asthma or COPD, compared to those without, 77 and $91 \%$ predicted, respectively. Among the patients without known asthma or COPD there was a strong association between low $\mathrm{FEV}_{1}$ and the symptoms cough and dyspnoea. Both acute-phase and follow-up FEV 1 was measured in 395 of the patients without known asthma or COPD, and a significant increase in median value from 92 to $96 \%$ was registered. A reversibility of $\mathrm{FEV}_{1}$ of $>15 \%$ was measured in $23 \%$ of the 395 patients, uninfluenced by anti-asthma treatment in the great majority. Patients with an established viral, mycoplasmal or chlamydial infection had a significantly lower $\mathrm{FEV}_{1}$ at entry and a greater reversibility, compared to those without such aetiological diagnosis.

We conclude that reversible obstruction was particularly common in the patients diagnosed as having acute bronchitis, but that it was also found in the patients diagnosed as having upper respiratory tract infection. The high frequency of spontaneous reversibility in otherwise healthy adults calls for caution when response to anti-asthma treatment is interpreted in patients with possible asthma.

Eur Respir J., 1994, 7, 1239-1245.

\begin{abstract}
* Institute of Community Medicine, University of Troms $\varnothing$, Troms $\varnothing$, Norway. ** Dept of Thoracic Medicine, Rikshospitalet, Oslo, Norway. *** Dept of Medical Microbiology, University Hospital, Troms $\emptyset$, Troms $\emptyset$, Norway.
\end{abstract}

Correspondence: H. Melbye Institute of Community Medicine University of Troms $\varnothing$ 9037 Troms $\varnothing$

Norway

Keywords: Acute bronchitis bronchial obstruction respiratory infection serological diagnosis

Received: September 131993 Accepted after revision March 301994

This research was supported by a grant from the Norwegian Research Council for Science and the Humanities, MRC, Programme for Research in General Practice to H.M.
It has been established that healthy persons may experience an impairment of bronchial airflow in association with respiratory infection $[1,2]$. Respiratory viruses and Mycoplasma pneumoniae do not only cause exacerbation of asthma and chronic obstructive pulmonary disease (COPD) [3-5], but also airflow limitation and bronchial hyperreactivity in otherwise healthy persons [6-8]. Significant reversibility of airway obstruction has been shown in patients diagnosed as having acute bronchitis in two clinical studies $[9,10]$. We wanted to find out whether these results could be confirmed in a larger population of adults with respiratory infection who consult a primary care doctor.

Reversibility of bronchial obstruction is a known feature of asthma, and an increase of forced expiratory volume in one second $\left(\mathrm{FEV}_{1}\right)$ of more than $15 \%$ of the initial level has been considered to be a significant response to a course of oral corticosteroids [11]. We wanted to determine how often such reversibility occurs spontaneously in otherwise healthy adults with respiratory infection.

We also wanted to study the role of respiratory viruses, mycoplasmal and chlamydial agents in airflow limitation, to find out whether certain agents may cause more obstruction than others.

\section{Material and methods}

\section{Patients}

Consecutive patients aged 18 yrs or more, attending the Municipal Emergency Clinic in Troms $\emptyset$, between October 1988 and June 1989, and presenting symptoms indicating an upper or lower respiratory tract infection (including cough, dyspnoea, sore throat and concern about having a respiratory infection) were asked by a reception nurse to participate in this investigation, which also dealt with other aspects of respiratory infection [12]. Patients with dyspnoea severe enough to need emergency treatment and pregnant women were excluded. Of 626 patients who were asked, 581 participated. At the Municipal Emergency Clinic, general practitioners in Troms $\varnothing$ manage out-of-hours calls. Forty doctors were sharing the duties at the clinic in this period, and all took part in the examination of the patients. 


\section{Examinations}

On a self-administered questionnaire, the patients reported smoking habits and symptoms associated with the present illness. Cough and dyspnoea were to be graded as: absent, usual, more annoying than usual, or very annoying. Coryza, sore throat and fatigue were to be graded as: absent, slight or pronounced. In a standardized interview, specially trained nurses asked about previous heart and lung disease and about use of anti-asthma medication. The nurses also carried out spirometry with the patient standing. Vitalograph Alpha, an electronic spirometer with a pneumotachograph type flowhead, was used. Calibration was carried out daily, by the use of a one litre syringe. The best result of $\mathrm{FEV}_{1}$ after three attempts was registered. Out-prints of the volume-time curves were reviewed by the first author. The doctors, who were not informed about the spirometric results, were told to examine and treat the patients as usual and record main clinical diagnosis and treatment. The doctors were not obliged to follow certain criteria in making their diagnosis. Patients diagnosed as having asthma, COPD or chronic bronchitis by the doctor, or who reported use of anti-asthma medication regularly or on-demand, were classified as having established asthma or COPD.

All patients were invited for follow-up spirometry after 4-5 weeks, carried out by the same nurses. From the patients who attended, paired specimens of sera were obtained. Serological analyses for immunoglobulin $G$ (IgG) antibodies were carried out against the following agents: Mycoplasma pneumoniae, Chlamydia spp., influenza virus $\mathrm{A}$ and $\mathrm{B}$, parainfluenza virus 1 and 3 , respiratory syncytial (RS)-virus, and adenovirus. A fourfold change in titre or a single high titre $(\geq 80)$ was used as evidence of infection [13]. Throat specimens were cultured for the detection of Group A streptococci and serological analysis for antistreptolysin 0 and anti-deoxyribonuclease (DNase) B was also carried out. A chest radiograph was taken when requested by the doctor, and according to certain other criteria [12], and was thus obtained in 319 patients. Twenty patients were radiographically diagnosed as having pneumonia [12].

Patients with pronounced discomfort from cough or dyspnoea after 10 days of illness, or who had $\mathrm{FEV}_{1}<85 \%$ predicted at the first consultation, were asked to attend the Chest Clinic at the University Hospital of Troms $\varnothing$ for further examinations and treatment. Eligible patients were asked to participate in a one week placebo-controlled trial with fenoterol, a study presented previously [14].

The study was approved by the Regional Committe of Medical Research Ethics.

\section{Analysis}

Median $\mathrm{FEV}_{1} \%$ predicted and 5-95\% percentiles were calculated in all patients with a valid spirometry at the first consultation. Reference values from a Norwegian urban population [15] were used. The change in $\mathrm{FEV}_{1} \%$ predicted between the first consultation and the followup control after 4-5 weeks and the association with micro- biological agents was analysed in those patients with valid spirograms at both consultations. The patients with an established diagnosis of asthma, COPD or chronic bronchitis were analysed separately. Statistical significance of differences between groups were tested with Chi-squared test and Wilcoxon's rank sum test, and the differences between paired results with signed rank test. SAS software package was used in all the statistical analyses.

\section{Results}

Of the 581 participating patients, spirometry was successfully carried out in 574, 335 women and 239 men, median age 28 yrs (range 18-78 yrs). Reasons for unsuccessful recordings in seven patients were technical problems (twisted tube), poor co-operation and chest pain (one of the pneumonia patients).

Of the 574 patients, 24 were diagnosed as having an aggravation of asthma or COPD at entry, and as an additional 21 reported to have asthma and use anti-asthma medication regularly or on demand, 45 patients could be classified as having an established diagnosis of asthma or COPD. Of these 45 patients, $40 \%$ reported very annoying cough and $25 \%$ very annoying dyspnoea. The corresponding frequencies in the remaining patients, classified as the patients without known obstructive disease, were 26 and $6 \%$, respectively.

\section{Airflow limitation}

The median $\mathrm{FEV}_{1}$ in all 574 patients was $90 \%$ predicted, and the 5-95\% percentiles were 60-112. Significantly higher $\mathrm{FEV}_{1}$ was found among the 529 patients without known obstructive disease, $91 \%$ predicted (median value), than among the 45 patients with an established diagnosis of asthma or COPD, 77\% predicted ( $\mathrm{p}<0.0001)$. Among the patients without known obstructive disease, there was no significant difference between men and women, and habitual smokers had lower $\mathrm{FEV}_{1} \%$ predicted than nonsmokers only when aged $40 \mathrm{yrs}$ or more (table 1). The patients who reported very annoying cough or dyspnoea had a significantly lower median $\mathrm{FEV}_{1}$ than

Table 1. - FEV $\%$ predicted according to age and smoking habit in $519^{*}$ adults without known obstructive disease, who had a respiratory infection

\begin{tabular}{|c|c|c|c|c|c|c|}
\hline \multirow{2}{*}{$\begin{array}{c}\text { Age } \\
\text { yrs }\end{array}$} & \multirow[b]{2}{*}{$\mathrm{n}$} & \multicolumn{2}{|c|}{ Smoking } & \multicolumn{3}{|c|}{$\mathrm{FEV}_{1} \%$ pred } \\
\hline & & $\mathrm{n}$ & $\%$ & Nonsmoker & Smoker & All \\
\hline $18-29$ & 289 & 156 & 54 & 89 & 92 & 91 \\
\hline $30-39$ & 113 & 65 & 58 & 91 & 92 & 92 \\
\hline $40+* *$ & 117 & 54 & 46 & 99 & 88 & 93 \\
\hline All & 519 & 275 & 53 & 92 & 91 & 91 \\
\hline
\end{tabular}

Data for $\mathrm{FEV}_{1} \%$ predicted are median values. $\mathrm{FEV}_{1}$ : forced expiratory volume in one second. *: 10 of the 529 patients, with median $\mathrm{FEV}_{1} 86 \%$ predicted, did not answer the questions about smoking; **: the difference between smokers and nonsmokers is statistically significant $\mathrm{p}<0.05$. 
Table 2. - $\mathrm{FEV}_{1} \%$ predicted according to reported symptoms in 529 adults with respiratory infection

\begin{tabular}{lrcc}
\hline Symptom & $\mathrm{n}$ & $\begin{array}{c}\text { Median } \mathrm{FEV}_{1} \\
\% \text { pred }\end{array}$ & $\begin{array}{c}\mathrm{FEV}_{1} \% \text { pred } \\
5-95 \% \text { percentiles }\end{array}$ \\
\hline Very annoying cough & 137 & $87^{*}$ & $51-111$ \\
Very annoying dyspnoea & 30 & $81^{*}$ & $41-106$ \\
Coryza (pronounced) & 217 & 91 & $67-113$ \\
Sore throat (pronounced) & 194 & 92 & $65-112$ \\
$\begin{array}{l}\text { Fatigue (pronounced) } \\
\text { Previous/chronic heart }\end{array}$ & 174 & 92 & $65-108$ \\
$\quad 15$ & 91 & $53-107$ \\
$\quad \begin{array}{l}\text { disease } \\
\quad \text { disevious/chronic lung }\end{array}$ & 26 & 94 & $65-110$ \\
$\quad$ All patients & 529 & 91 & $64-113$ \\
\hline
\end{tabular}

$\mathrm{FEV}_{1}$ : forced expiratory volume in one second. *: the difference between patients with and without the symptoms is statistically significant, $\mathrm{p}<0.0001$.

Table 3. - Age, gender, smoking habits and $\mathrm{FEV}_{1} \%$ predicted in the patients who attended the second consultation (attenders), or dropped out after the first consultation

\begin{tabular}{lccc}
\hline & $\begin{array}{c}\text { Attenders } \\
\mathrm{n}=395\end{array}$ & $\begin{array}{c}\text { Drop outs } \\
\mathrm{n}=134\end{array}$ & $\mathrm{p}$ \\
\hline Age yrs* & 29 & 25 & $<0.001$ \\
Females \% & 61 & 54 & NS \\
Smoking \% & 46 & 71 & $<0.0001$ \\
FEV $_{1} \%$ pred* $^{*}$ & 92 & 90 & NS \\
\hline
\end{tabular}

*: median values. $\mathrm{FEV}_{1}$ : forced expiratory volume in one second; NS: nonsignificant.

the patients without these symptoms (table 2). Forty patients reported previous or chronic disease of the heart or lung. Among the 15 with previous/chronic heart disease, coronary heart disease was reported in 10 , and no patients reported heart insufficiency. Chronic bronchitis was most frequently reported among the 26 patients with previous/chronic lung disease $(n=15)$, followed by pulmonary tuberculosis and pneumonia. The patients with previous/chronic heart or lung disease had similar $\mathrm{FEV}_{1}$ $\%$ predicted to those without (table 2). Among the patients without known obstructive disease, the 16 with radiographically diagnosed pneumonia had a median $\mathrm{FEV}_{1}$ of $79 \%$ predicted.

\section{Reversibility}

Valid follow-up spirometry was obtained in 429 of the 574 patients $(75 \%)$. Of these, 34 could be classified as having established asthma/COPD, and 395 as without known obstructive disease. The patients who attended the follow-up control were older and less frequent smokers than those who dropped out (table 3). The median $\mathrm{FEV}_{1} \%$ predicted among the 395 patients increased from $92 \%(64-112 \%)$ to $96 \%(73-116 \%)$. The median increase was $4 \%(-13 \pm 44 \%)$, significantly higher than zero $(\mathrm{p}<0.0001)$. The distribution of the results at the first and second consultations is shown in figure 1 . The median $\mathrm{FEV}_{1}$ among the 33 patients with previous/chronic heart or lung disease increased from 93 to $97 \%$ of predicted. Ninety one $(23 \%)$ had a reversibility exceeding $15 \%$ of initial value. Among the 87 patients clinically diagnosed as having pneumonia or acute bronchitis, 37 (43\%) had such reversibility, compared to $18 \%$ of the patients diagnosed as having upper respiratory tract infection (including throat infection and "flu"), $(\mathrm{p}<0.0001)$. Among 16 patients with radiographic evidence of pneumonia, five had a reversibility of more than $15 \%$.

The median $\mathrm{FEV}_{1}$ among the 67 patients diagnosed as having acute bronchitis increased from 86 to $98 \%$ of predicted, and the mean values (for comparison with previous studies) from 88 to $98 \%$.

A decrease in $\mathrm{FEV}_{1}$ between the initial and follow-up spirometry of more than $15 \%$ was found in 17 patients $(4 \%)$.

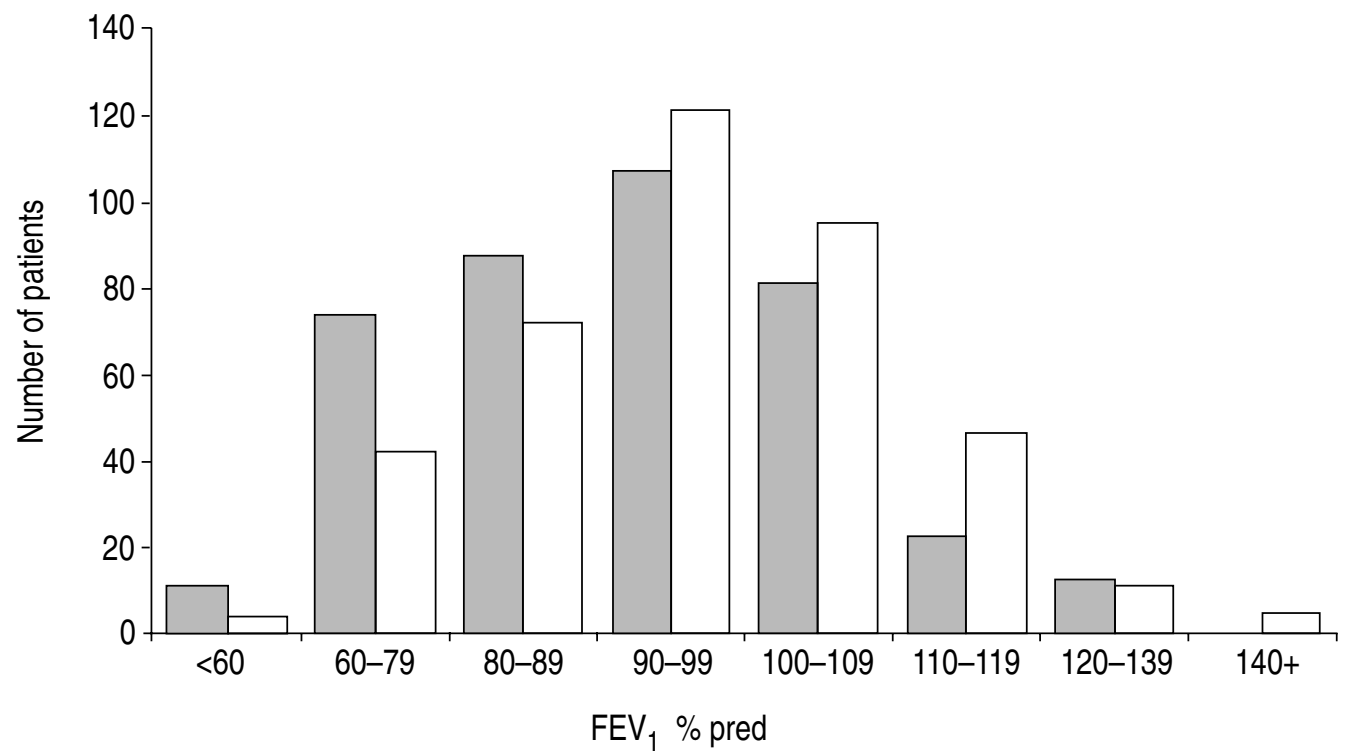

Fig. 1. - Distribution of FEV $\%$ predicted in 395 adults without known obstructive disease with respiratory infection. Acute-phase and follow-

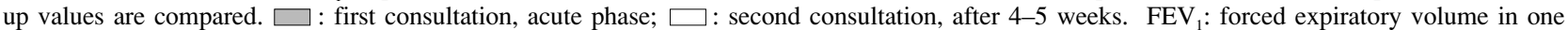
second. 
Table 4. - FEV 1 in 393 adults without known obstructive disease who had a respiratory tract infection, related to established infection with mycoplasmal, chlamydial and viral agents; change between the first consultation and followup control, and the rate of recovery after $4-5$ weeks

\begin{tabular}{|c|c|c|c|c|c|}
\hline & $\mathrm{n}$ & $\begin{array}{l}\mathrm{FEV}_{1} \\
\text { at entry } \\
\% \text { pred }\end{array}$ & $\begin{array}{c}\mathrm{FEV}_{1} \\
\text { after 4-5 weeks }{ }^{\dagger} \\
\% \text { pred }\end{array}$ & $\begin{array}{c}\text { Increase } \\
\text { in } \mathrm{FEV}_{1}^{\dagger} \\
\%\end{array}$ & $\begin{array}{c}\text { Patients recovered } \\
\text { at follow-up } \\
\%\end{array}$ \\
\hline Influenza virus $(\mathrm{A}+\mathrm{B})$ & 47 & 88 & 96 & 6 & 83 \\
\hline RS-virus & 19 & 92 & 97 & 7 & 79 \\
\hline Parainfluenza virus (group 3) & 17 & 90 & 97 & 5 & 94 \\
\hline Adenovirus & 12 & 83 & 93 & 11 & 83 \\
\hline Mycoplasma pneumoniae & 13 & 82 & 90 & 16 & 92 \\
\hline Chlamydia pneumoniae & 7 & 94 & 89 & 1 & 71 \\
\hline Any of these agents & 102 & $90^{*}$ & 96 & $7 * *$ & 83 \\
\hline None of these agents & 291 & $92^{*}$ & 97 & $3 * *$ & 85 \\
\hline
\end{tabular}

$\dagger$ : median values. $\mathrm{FEV}_{1}$ : forced expiratory volume in one second; RS: respiratory syncytial. *, **: the difference between those with and without established infection is statistically significant, $\mathrm{p}=0.05, \mathrm{p}<0.05$ respectively.

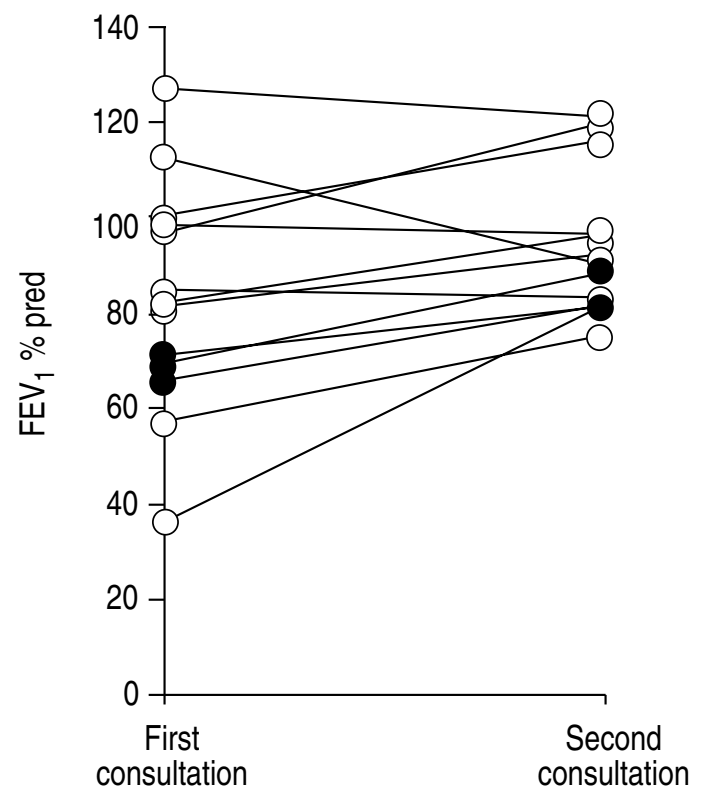

Fig. 2. - Change in $\mathrm{FEV}_{1} \%$ predicted in 13 patients with established infection with Mycoplasma pneumoniae. The three patients with radiographic evidence of pneumonia are marked with filled circles $(\bullet)$. $\mathrm{FEV}_{1}$ : forced expiratory volume in one second.

\section{The association with serological evidence of infection}

Of the 395 patients with follow-up spirometry, who had no known obstructive disease, paired specimens of sera were obtained in 393. Serological evidence of mycoplasmal, chlamydial or viral infection was found in 102 of these. Infection with influenza virus was most frequently identified (table 4), and 43 of 47 were influenza virus type A. The patients with such serological evidence of infection had significantly lower median $\mathrm{FEV}_{1}$ $\%$ predicted, compared to those without (table 4). This difference was no longer significant at the second consultation, and the median increase in $\mathrm{FEV}_{1}$ was significantly larger in the 102 with established infection. The greatest median reversibility was found in patients with mycoplasmal infection, and the individual changes in these patients are shown in figure 2 .

Ten out of 15 patients with radiographic pneumonia belonged to the 102 with established infection, but the differences in $\mathrm{FEV}_{1} \%$ predicted at entry and the reversibility of $\mathrm{FEV}_{1}$ remained statistically significant when these 15 patients were excluded from the analysis. The frequency of smoking was $47 \%$ in the patients with serological evidence of infection, and $46 \%$ among the remaining patients $(\mathrm{p}=0.9)$, and there was also similar distribution of age and gender in both groups.

Very annoying cough was significantly more frequent in the patients with established viral, chlamydial or mycoplasmal infection compared to patients without such infection, whilst the opposite was the case for pronounced sore throat (table 5). Very annoying cough was reported particularly frequently in the patients with mycoplasmal infection, whilst coryza was reported particularly infrequently.

Recovery from illness at the follow-up consultation was reported by $84 \%$ of the patients, and with similar frequency in patients with and without established infection, as well as in smokers and nonsmokers. The median $\mathrm{FEV}_{1}$ among the 332 patients who reported recovery was $97 \%$ of predicted, significantly higher than among the 61 who had not recovered, $94 \%$ of predicted $(\mathrm{p}<0.05)$.

Group A streptococcal infection was found by culture or significant change in antistreptolysin-0 or anti-DNaseB titre in 57 of the 393 patients, and a reversibility of $\mathrm{FEV}_{1}>15 \%$ was found in nine of these.

Among the 34 patients with established asthma/COPD who attended the second consultation, infection with influenza virus was established in 4, RS-virus in 4 and parainfluenza virus in 2 . The median $\mathrm{FEV}_{1} \%$ predicted, $68 \%$, was lower, and the median reversibility of $\mathrm{FEV}_{1}$, $31 \%$, was higher in these 10 patients than in the 24 with no serological evidence of infection, whose corresponding values were 79 and $8 \%$, respectively. These differences were not statistically significant. 
Table. 5. - Very annoying dyspnoea, very annoying cough, pronounced sore throat, fatigue and coryza reported by 393 adults without known obstructive disease who had a respiratory tract infection, related to established infection with mycoplasmal, chlamydial and viral agents

\begin{tabular}{|c|c|c|c|c|c|c|c|c|c|c|c|}
\hline & \multirow[t]{2}{*}{$\mathrm{n}$} & \multirow{2}{*}{\multicolumn{2}{|c|}{$\begin{array}{c}\text { Very } \\
\text { annoying } \\
\text { dyspnoea }\end{array}$}} & \multicolumn{2}{|c|}{$\begin{array}{l}\text { Very } \\
\text { annoying } \\
\text { cough }\end{array}$} & \multicolumn{2}{|c|}{$\begin{array}{l}\text { Pronounced } \\
\text { sore throat }\end{array}$} & \multicolumn{2}{|c|}{$\begin{array}{l}\text { Pronounced } \\
\text { fatigue }\end{array}$} & \multicolumn{2}{|c|}{$\begin{array}{c}\text { Pronounced } \\
\text { coryza }\end{array}$} \\
\hline & & & & $\mathrm{n}$ & $(\%)$ & $\mathrm{n}$ & $(\%)$ & $\mathrm{n}$ & $(\%)$ & $\mathrm{n}$ & $(\%)$ \\
\hline Influenza virus $(\mathrm{A}+\mathrm{B})$ & 47 & 7 & (15) & 18 & $(38)^{*}$ & 11 & (23) & 23 & $(49)^{*}$ & 15 & (32) \\
\hline RS-virus & 19 & 3 & & 5 & & 6 & & 9 & (47) & 12 & (63) \\
\hline Parainfluenza virus (group 3) & 17 & 0 & & 8 & $(47)^{*}$ & 5 & & 4 & & 7 & (42) \\
\hline Adenovirus & 12 & 1 & & 1 & & 5 & (42) & 3 & & 5 & (42) \\
\hline Mycoplasma pneumoniae & 13 & 1 & & 9 & $(70)^{*}$ & 4 & & 2 & & 2 & (15) \\
\hline Chlamydia pneumoniae & 7 & 1 & & 3 & & 2 & & 2 & & 5 & (71) \\
\hline Any of these agents & 102 & 10 & $(10)$ & 36 & $(36)^{* *}$ & 27 & $(27)^{*}$ & 38 & $(37)$ & 45 & (44) \\
\hline None of these agents & 291 & 16 & (6) & 67 & (23) & 120 & $(41)$ & 87 & $(30)$ & 122 & $(42)$ \\
\hline
\end{tabular}

*,**: the difference between patients infected and not infected by the agent is statistically significant, $\mathrm{p}<0.05, \mathrm{p}<0.01 \mathrm{respec}-$ tively.

\section{Anti-asthma treatment}

A bronchodilator for inhalation was prescribed at the first consultation to three of the 395 patients without known obstructive disease, who attended the follow-up consultation. A reversibility of $\mathrm{FEV}_{1}$ exceeding $15 \%$ of initial value was found in one of these three patients. Anti-asthma treatment was prescribed to another six of the 395 patients who had $\mathrm{FEV}_{1}<60 \%$ predicted when they attended the Chest Clinic, few days after entry, and a reversibility of more than $15 \%$ was registered in all six. Forty four of the 395 patients without known obstructive disease entered the clinical trial with fenoterol/placebo. The median $\mathrm{FEV}_{1}$ values at entry were similar in those allocated to the fenoterol and the placebo groups, 84 and $83 \%$ predicted, respectively, and were still so after 4-5 weeks (93\% predicted in both groups). A reversibility of $\mathrm{FEV}_{1}$ of more than $15 \%$ between the first consultation at the emergency clinic and the second consultation after 4-5 weeks was registered in 8 of the 21 patients who were allocated to the fenoterol group, compared to 6 of the 23 allocated to the placebo group, and it may, thus, be assumed that the one week of treatment with fenetorol may have contributed to the reversibility in two patients. Altogether 30, of the 395 patients had antiasthma treatment, including the participants of the clinical trial, and in nine of these patients this treatment may have contributed to a more than $15 \%$ reversibility of $\mathrm{FEV}_{1}$.

\section{Discussion}

The study shows that a transient fall in $\mathrm{FEV}_{1}$ is a common feature of respiratory infections. The reversible airflow limitation does not necessarily reflect bronchial obstruction in all of the patients. The greater than $15 \%$ reversibility of initial $\mathrm{FEV}_{1}$ in 5 out of 16 patients with radiographic pneumonia indicates that restrictive lung disease may play a role in some patients. But restrictive disease probably did not represent an important source of error, because the patients with chronic/previous heart or lung disease had normal $\mathrm{FEV}_{1}$ values. Since a reversibility of $\mathrm{FEV}_{1}$ of more than $15 \%$ was found in 9 of the 57 patients diagnosed as having streptococcal pharyngitis, narrowing of the pharynx may also have contributed to the results. General fatigue during the acute illness did not seem to play any important role.

Because a reversibility of more than $15 \%$ was found in $23 \%$ of the patients, whereas a corresponding fall was found only in $4 \%$, only a minor part of the reversibility may be ascribed to the statistical phenomenon "regression towards the mean". The reversibility may be regarded as spontaneous in the great majority of cases, since antiasthma treatment probably played a role in only nine of the 91 patients with a reversibility of $\mathrm{FEV}_{1}$ exceeding $15 \%$.

The distinct reversibility among the patients diagnosed as having acute bronchitis, and the strong association between reduced $\mathrm{FEV}_{1}$ and the symptoms dyspnoea and cough, indicates that bronchial obstruction is a main explanation for the transient airflow limitation described in this study. The findings of WILLIAMSON [9] and BoLDY et al. [10] concerning patients with acute bronchitis have been confirmed, as the increase in mean $\mathrm{FEV}_{1}$ from 88 to $98 \%$ predicted was close to Williamson's finding ( 84 to $98 \%$ predicted). Bronchial obstruction may also be a reason for the reversible airflow limitation found in many patients diagnosed as having upper respiratory tract infection. Bronchial obstruction in this group of patients may, among other things, be explained by a tendency to underdiagnose acute bronchitis when physical chest signs are missing.

The classification of the patients as infected versus not infected with respiratory viruses, chlamydials or M. pneumoniae may be subject to many sources of error. The sensitivity of the serological analysis for infection is less than $100 \%$. The patients were not examined for rhinovirus and the other viruses causing common cold, and such infections may have been frequent in the patients without established infection [16]. Many patients may thus have been misclassified, and the difference between the two groups may have been underestimated. 
Very annoying cough was frequently reported by patients infected with influenza virus or Mycoplasma pneumoniae. This association indicates the role of these agents in lower respiratory tract infection. Very annoying cough was also very frequent in parainfluenza virus infection, possibly reflecting the tendency of this virus to affect the larynx and trachea [17].

The airflow limitation and reversibility found in patients infected with Mycoplasma pneumoniae was not surprising. It has previously been shown that mycoplasmal infection may cause exacerbations of asthma [18], and bronchial hyperreactivity in nonasthmatics [19]. The patients with mycoplasmal infection in the study by SABATO et al. [19] also had significantly lower $\mathrm{FEV}_{1}$ after one month compared to controls, although they reported to be asymptomatic at that time. The relatively low follow-up $\mathrm{FEV}_{1}$ in the patients with mycoplasmal infection in our study may reflect a tendency of slow recovery from impairment of lung function in such patients.

The tendency of particularly low $\mathrm{FEV}_{1}$ and great reversibility found among the patients with known asthma or COPD in whom we could determine an aetiologic agent, supports the conclusion of BEASLEY et al. [4] that the most serious attacks of asthma are frequently precipitated by viral infection.

The study population was generally young. We could not find any age trend in airflow limitation and reversibility, but the documentation as regards the elderly must be characterized as fragile. The over-representation of young smokers among the drop-outs is probably of minor importance, since a difference in airflow limitation between smokers and nonsmokers was only found in patients older than 40 yrs of age.

Reduction and reversibility of $\mathrm{FEV}_{1} \%$ predicted was used as measure of airflow limitation. We found that it was difficult to obtain a valid measure of forced vital capacity (FVC) in many patients, since the forced expiratory manoeuvre was frequently interrupted by cough. This could also be read from the volume-time curves. We thus decided not to present $\mathrm{FEV}_{1}$ values in $\%$ of FVC. An increase in $\mathrm{FEV}_{1}$ of more than $15 \%$ of the initial value was used as an indicator of significant reversibility. This arbitrary cut-off point may not be valid in all patients. A reversibility of $9 \%$ as response to a bronchodilator was found to be the upper normal value in healthy nonsmokers in one epidemiological study [20]. The reversibility of $\mathrm{FEV}_{1}$ in percentage of baseline is strongly dependent on the initial value [21], and a reversibility of $15 \%$ may, thus, be insignificant in subjects with a low initial $\mathrm{FEV}_{1}$. In the present study of generally young, otherwise healthy adults, few subjects had a very low initial $\mathrm{FEV}_{1}$, and error due to the use of percentage change from initial $\mathrm{FEV}_{1}$ probably plays a minor role.

\section{Clinical implications}

Bronchial obstruction may also play an important role in the symptoms of respiratory infections in otherwise healthy persons. However, only a few clinical trials have evaluated the usefulness of bronchodilators or corticosteroids in acute bronchitis. A significant sympto-

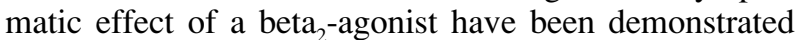
in two clinical trials $[15,22]$, whilst inhaled steroids have not as yet been proved to be more useful than placebo [23]. The smaller increase in $\mathrm{FEV}_{1}$ in the patients of this study, who had not recovered completely after 4-5 weeks, compared to those who reported to have recovered, may indicate that a bronchodilator should be more frequently prescribed. More studies are needed to assess the usefulness of anti-asthma therapy in acute bronchitis.

It is likely that some patients in our study population without known asthma or COPD, actually had one of these diseases. It has been reported that a considerable proportion of patients diagnosed as having acute bronchitis will be later shown to have asthma [24, 25]. Although the doctor should think of asthma as a possibility when airflow limitation is diagnosed in a patient with respiratory infection, he should also be aware that spontaneous reversibility is a common feature of such infections, as shown by this study. The high frequency of spontaneous reversibility should be taken into consideration when a response to anti-asthma treatment is interpreted in patients with possible asthma.

Acknowledgements: The authors thank Gerd and Lars Volder's legacy for financial support.

\section{References}

1. Johansen WG, Pierce AK, Sanford JP. Pulmonary function in uncomplicated influenza. Am Rev Respir Dis 1969; 100: 141-146.

2. O'Connor SA, Jones DP, Collins JV, Heath RB, Campbell MJ, Leighton MH. Changes in pulmonary function after naturally acquired respiratory infection in normal persons. Am Rev Respir Dis 1979; 120: 1087-1093.

3. Minor TE, Dick EC, Baker JW, Ouelette JJ, Cohen M, Reed CE. Rhinovirus and Influenza type A infection as precipitants of asthma. Am Rev Respir Dis 1976; 113: 149-153.

4. Beasley R, Coleman ED, Hermon Y, Holst PE, O'Donnell TV, Tobias M. Viral respiratory tract infection and exacerbations of asthma in adult patients. Thorax 1988; 43: 679-683.

5. Björnsdottir US, Busse WW. Respiratory infections and asthma. Med Clin North Am 1992; 76: 895-915.

6. Blair HT, Greenberg SB, Stevens PM, Bilunos PA, Couch RB. Effects of rhinovirus infection on pulmonary function of healthy volunteers. Am Rev Respir Dis 1976; 114: 95-102.

7. Empey DW, Laitinen LA, Jacobs L, Gold WM, Nadel JA. Mechanisms of bronchial hyperreactivity in normal subjects after upper respiratory tract infection. Am Rev Respir Dis 1976; 113: 131-139.

8. Hall WJ, Hall CB, Speers DM. Respiratory syncytial virus infection in adults. Clinical, virologic, and serial pulmonary function studies. Ann Intern Med 1978; 88: 203-205.

9. Williamson HA. Pulmonary function tests in acute bronchitis: evidence for reversible airway obstruction. J Fam Pract 1987; 25: 251-256. 
10. Boldy DAR, Skidmore SJ, Ayres JG. Acute bronchitis in the community: clinical features, infective factors, changes in pulmonary function and bronchial reactivity to histamine. Respir Med 1990; 84: 377-385.

11. Wardman AG, Binns V, Clayden AD, Cooke NJ. The diagnosis and treatment of adults with obstructive airways disease in general practice. Br J Dis Chest 1986; 80: 19-26.

12. Melbye H, Straume B, Aasebø U, Dale K. Diagnosis of pneumonia in adults in general practice. Relative importance of typical symptoms and abnormal chest signs evaluated against a radiographic reference standard. Scand J Prim Health Care 1992;10: 226-233.

13. Melbye H, Berdal BP, Straume B, Russell H, Vorland L, Thacker WL. Pneumonia: a clinical or radiographic diagnosis. Etiology and clinical features of lower respiratory tract infection in adults in general practice. Scand J Infect Dis 1992; 24: 647-655.

14. Melbye H, Aasebø U, Straume B. Symptomatic effect of inhaled fenoterol in acute bronchitis: a placebocontrolled double-blind study. Family Practice 1991; 8: 216-222.

15. Gulsvik A. Prevalence and manifestations of obstructive lung disease in the city of Oslo. Scand J Respir Dis 1979; 60: 286-296.

16. Johnston S, Pattemore P, Smith S, et al. Viral infections in exacerbations in schoolchildren with cough or wheeze: a longitudinal study. Am Rev Respir Dis 1992; 145: A546.
17. Graham NMH. The epidemiology of acute respiratory infections in children and adults: a global perspective. Epidemiol Rev 1990; 12: 149-178.

18. Seggev JS, Lis I, Siman-Tov R, et al. Mycoplasma pneumoniae is a frequent cause of exacerbation of bronchial asthma in adults. Ann Allergy 1986; 57: 263-265.

19. Sabato AR, Martin AJ, Marmion BP, Kok TW, Cooper DM. Mycoplasma pneumoniae: acute illness, antibiotics, and subsequent pulmonary function. Arch Dis Child 1984; 59: 1034-1037.

20. Dales RE, Spitzer WO, Tousignant P, Schechter M, Suissa $\mathrm{S}$. Clinical interpretation of airway response to a bronchodilator. Epidemiologic considerations. Am Rev Respir Dis 1988; 138: 317-320.

21. Brand PLP, Quanjer PH, Postma DS, et al. Interpretation of bronchodilator response in patients with obstructive airways disease. Thorax 1992; 47: 429-436.

22. Hueston WJ. A comparison of albuterol and erythromycin for the treatment of acute bronchitis. J Fam Pract 1991; 33: 476-480.

23. Frank A, Dash CH. Inhaled beclomethasone dipropionate in acute infections of the respiratory tract. Respiration 1985; 48: 122-126.

24. Williamson HA, Scultz P. An association between acute bronchitis and asthma. J Fam Pract 1987; 24: $35-38$.

25. Hallett JS, Jacobs RL. Recurrent acute bronchitis: the association with undiagnosed bronchial asthma. Ann Allergy 1985; 55: 568-570. 